\title{
Cannabis use and patterns among middle and older aged Canadians prior to legalization: a sex-specific analysis of the Canadian Tobacco, Alcohol and Drugs Survey
}

Asvini Keethakumar ${ }^{1 *}$ D, Vrati M. Mehra', Nazilla Khanlou ${ }^{2}$ and Hala Tamim

\begin{abstract}
Background: The recreational use of cannabis was legalized across Canada in October 2018. While many people use cannabis without harm, adverse outcomes have been noted in a few populations, including middle-aged and older adults. Given that the current literature has neglected to study cannabis use among this population and between sexes, the objective of our study was to identify the prevalence, characteristics, and patterns of cannabis use among middle and older aged males and females prior to legalization in Canada.

Methods: Secondary analysis was conducted on the Canadian Tobacco, Alcohol and Drugs Survey 2017, with the sample restricted to adults ages 40 and above. The main outcome was defined as past-year cannabis use and statistical analysis was conducted separately for males and females. Bivariate and multivariable logistic regression was performed to identify associations between the main outcome and various sociodemographic, health, and substance use variables. Explanatory supplementary variables were also explored.

Results: In 2017, 5.9\% of females and 9.0\% of males over the age of 40 reported past-year cannabis use. Almost $62 \%$ of males who used cannabis in the past-year reported a failed attempt at reducing or stopping their cannabis use. Over half (56\%) of older females, self-reported using cannabis for medical purposes. Additionally, over one in five older adults reported using a vaporizer or e-cigarette as a delivery method for cannabis. Significant characteristics of male cannabis use included having no marital partner, cigarette smoking, and illegal drug use. Furthermore, significant predictors of past-year cannabis use in females included residing in an urban community, Eastern- Atlantic provinces or British Columbia, having fair/poor mental health, smoking cigarettes, use of other tobacco products, and illegal drugs.

(Continued on next page)
\end{abstract}

\footnotetext{
* Correspondence: asvinikeetha@gmail.com

${ }^{1}$ School of Kinesiology and Health Sciences, Faculty of Health, York University, Toronto, Canada

Full list of author information is available at the end of the article
}

(c) The Author(s). 2021 Open Access This article is licensed under a Creative Commons Attribution 4.0 International License, which permits use, sharing, adaptation, distribution and reproduction in any medium or format, as long as you give appropriate credit to the original author(s) and the source, provide a link to the Creative Commons licence, and indicate if changes were made. The images or other third party material in this article are included in the article's Creative Commons licence, unless indicated otherwise in a credit line to the material. If material is not included in the article's Creative Commons licence and your intended use is not permitted by statutory regulation or exceeds the permitted use, you will need to obtain permission directly from the copyright holder. To view a copy of this licence, visit http://creativecommons.org/licenses/by/4.0/. The Creative Commons Public Domain Dedication waiver (http://creativecommons.org/publicdomain/zero/1.0/) applies to the data made available in this article, unless otherwise stated in a credit line to the data. 
(Continued from previous page)

Conclusion: To our such knowledge, this is the first nationally representative study to outline the prevalence, characteristics, and patterns of past-year cannabis use prior to Canadian legalization, among middle and older aged Canadians. Results from this study are expected to be used to reliably to track changes in usage, behaviours, and related disorders in the years to come.

Keywords: Cannabis, Marijuana, Substance use, Gerontology, Older adult, Canadian, Legalization

\section{Introduction}

As of October 2018, Canada became the second country in the world to legalize the recreational use of cannabis, also commonly known as marijuana, weed, and hashish [1]. According to the Government of Canada, the legalization of cannabis was implemented with three goals in mind; keeping it out of the hands of minors, reducing black market profits, and protecting the health of Canadians by providing access to safe cannabis via secure sources [2]. Prior to legalization, cannabis was the most commonly used illicit drug in Canada [3]. In 2014 alone, cannabis related costs burdened the Canadian economy with upwards of 2.8 billion dollars to combat economic, health and social consequences [3, 4]. While many people use cannabis without harm, it is important to note that adverse outcomes have been reported, especially among aging adults $[5,6]$. In some adults, use of cannabis has been linked to an increased risk of psychiatric disorders such as schizophrenia and psychosis [7, 8], and chronic conditions such as heart disease, asthma, pneumonia, cognitive decline, and loss of executive functioning [9-12]. A recent meta-analysis and systematic review noted that close to 1 in 8 people who have used cannabis experience cannabis dependence and cannabis abuse, while over 1 in 5 users may go on to develop a cannabis use disorder [13]. Although cannabis is commonly associated with age-related declines, legalization has been readily accepted by the Canadian public [14, 15].

In 2012, 42.5\% of the entire Canadian population reported having ever used cannabis, with $12.2 \%$ reporting use in the past year [16]. The prevalence was highest among 18-24-year olds, with 33.3\% reporting past-year use, followed by $20 \%$ among ages $15-17,15.6 \%$ in ages $25-44,6.7 \%$ in ages $45-64$, and $0.8 \%$ in those aged $65+[16]$. While cannabis is clearly popular among younger Canadians, major substance use surveys have shown that cannabis use has steadily grown in adults [4, 17]. Studies from the United Kingdom and United States have also shown a similar trend with cannabis being one of the most widely used drugs in adults over the age of 50 [18, 19].

Additionally, cannabis use behaviours among males and females have been noted as distinct [20, 21]. Between 2002 and 2010, Canadian males report a 2.4\% increase in their lifetime cannabis use, while use among females remained stagnant [16]. However, more recently, rates of female cannabis use has rapidly approached the rate of males [4]. Because substance use has historically been considered a male dominant problem, much of the literature has neglected to evaluate sex specific differences [22]. Pederson and colleagues (2015) noted that gender inequity among substance use research and health promotion efforts is a global challenge which must be addressed moving forward [23]. As such, it is essential that studies examine the sex specific differences of cannabis use and any related characteristics in Canada and across the globe.

In Canada, sociodemographic and economic factors associated with increased cannabis use include being a male, residing in the provinces of British Columbia and Nova Scotia, dwelling in urban areas, having a lower socioeconomic status, lower levels of postsecondary education attainment, and lower employment rates [6, 16, 24, 25]. Additionally, mental health complications such as depression, emotional distress, and psychosis have been associated with cannabis use $[6,26]$. Finally, cannabis use may be linked to the uptake of other substances, such as tobacco, alcohol, and illicit substances such as opioids, amphetamines, and cocaine $[6,26]$. Historically, given that younger Canadians have been the highest users of cannabis, most studies have focused on the youth and young adult population [26-28]. These results may not be generalizable to older age groups or specific sexes, as they have been noted to be distinct in the ways they access, use and respond to cannabis [29].

Currently, middle and older aged adults represent more than $51 \%$ of the Canadian population, making up a significantly large portion of the demographic [30]. With the recent cannabis legalization and increased access to cannabis products across the nation, the relationship between cannabis use among older Canadians may undergo important changes. In order for the Canadian public health system to evaluate and update policies around legalization in the upcoming years, it is vital that information around cannabis utilization is available and can be reliably tracked. Therefore, the objective of this study is to identify the prevalence, characteristics, and patterns of past-year cannabis use among older Canadians, separately for males and females, prior to cannabis legalization in Canada. 


\section{Methods}

\section{Data source and study population}

This study utilized the 2017 Canadian Tobacco, Alcohol and Drugs Survey (CTADS), which was conducted among all Canadian provinces. The CTADS is a crosssectional survey which collected detailed information on drug use, demographics, and lifestyle factors among Canadians. The survey was conducted biannually by Statistics Canada, in collaboration with Health Canada. The target population of the CTADS consisted of individuals aged 15 years and older, living in all ten provinces of Canada. However, residents of the three Canadian territories, residents of institutions, and those without either a home or cellular phone were excluded from the survey. Data collection started on February 1st, 2017 and concluded on December 31st, 2017. All responses to the survey were voluntary and self-reported directly by each participant. Further details about the survey data collection methods can be found on the Statistics Canada website [31]. For the purpose of this study, the survey responses were limited to include all individuals who were aged 40 and above at the time of response. Where possible, this investigation adhered to STROBE reporting guidelines for observational studies [32].

\section{Measures}

The main outcome for the study was "past-year cannabis use". This was measured by the question "During the past 12 months have you used marijuana?" The respondents were given the choice of answering "Yes" or "No".

A wide range of covariates were considered to be potential predictors of cannabis use, categorized by the following: sociodemographic factors, health factors, and substance use variables. These groupings were further categorized to include the following variables: Sociodemographic factors including age, sex, province of residence, type of community dwelling (rural or urban), marital status (partner or no partner), indigenous identity (yes or no), level of education (university degree and above, trade/college, secondary or less than secondary), and current employment (employed or not employed). Health factors comprised of self-perceived general health (excellent/very good, good, fair/poor) and self-perceived mental health (excellent/very good, good, fair/poor). Substance use variables (all of which were dichotomized into yes or no) included past 12 month alcohol use, current cigarette smoking, use of tobacco alternatives (containing one or more of cigarillo, cigar, tobacco water pipe or smoke-less tobacco use in the past 30 days), and other illicit drug use (including past 12-month use of one or more substances including cocaine, speed/meth, ecstasy, hallucinogens, salvia, heroin, inhalants, abuse of pain relievers, stimulants and sedatives).
Explanatory supplementary variables were considered, which included self-reported cannabis use for medical purposes (yes or no), main self-reported medical condition cannabis is used for, method of consumption, source of cannabis, frequency of past three-month use, failed attempt at controlling/reducing intake over past 3 months, as well as mean age at first cannabis use.

\section{Statistical analysis}

To achieve the targets of this study, statistical analysis was conducted separately for males and females. Descriptive statistics were conducted on all main and supplementary variables. The relationship between all characteristics and the main outcome were conducted using chi squared tests and binary logistic regressions. Multivariable logistic regression was conducted to adjust for all the covariates. Both unadjusted and adjusted Odds Ratios (ORs) along with the 95\% Confidence Intervals (CIs) have been reported. Approximately $4.31 \%$ of the cases had missing information and were subsequently excluded from the final analysis. Population weights were applied to each calculated estimate to adjust for sampling methodology and to report unbiased population parameters. Bootstrapping was performed to account for the complex sampling design. Statistical analyses were conducted using Statistical Package for Social Science (SPSS, version 26.0) and STATA version 13, (StataCorp, College Station, TX). Statistical significance for all analyses was set at alpha $<0.05$ for a two tailed test.

\section{Results}

Overall a total sample of 4789 individuals were included in this analysis, weighted to represent $8,890,444$ females and 8,181,855 males aged 40 and above in Canada. After population weights were added, $60.4 \%$ of the respondents were aged 40 and above at the time of the survey. The total prevalence of cannabis use among females was $5.9 \%$ as compared to $9.0 \%$ in males, for a total of $7.4 \%$ in the entire sample.

The prevalence of past-year male and female cannabis use, for all 10 provinces, are displayed in Fig. 1. When examining all the provinces in Canada, British Columbia was noted as having the highest prevalence of past-year cannabis use in both sexes (16.5\% females vs. $14.2 \%$ males) followed by Nova Scotia (8.9\% female vs. $12.4 \%$ male). Contrarily, the lowest prevalence of female and male past-year cannabis use was reported in Québec (3.1\% vs. $6.3 \%)$ and Ontario (3.6\% female vs. $8.3 \%$ male).

\section{Males}

Results of the supplementary statistics are reported in Table 1. Over 27\% of past-year cannabis users report using cannabis less than monthly, while $25.5 \%$ of users 


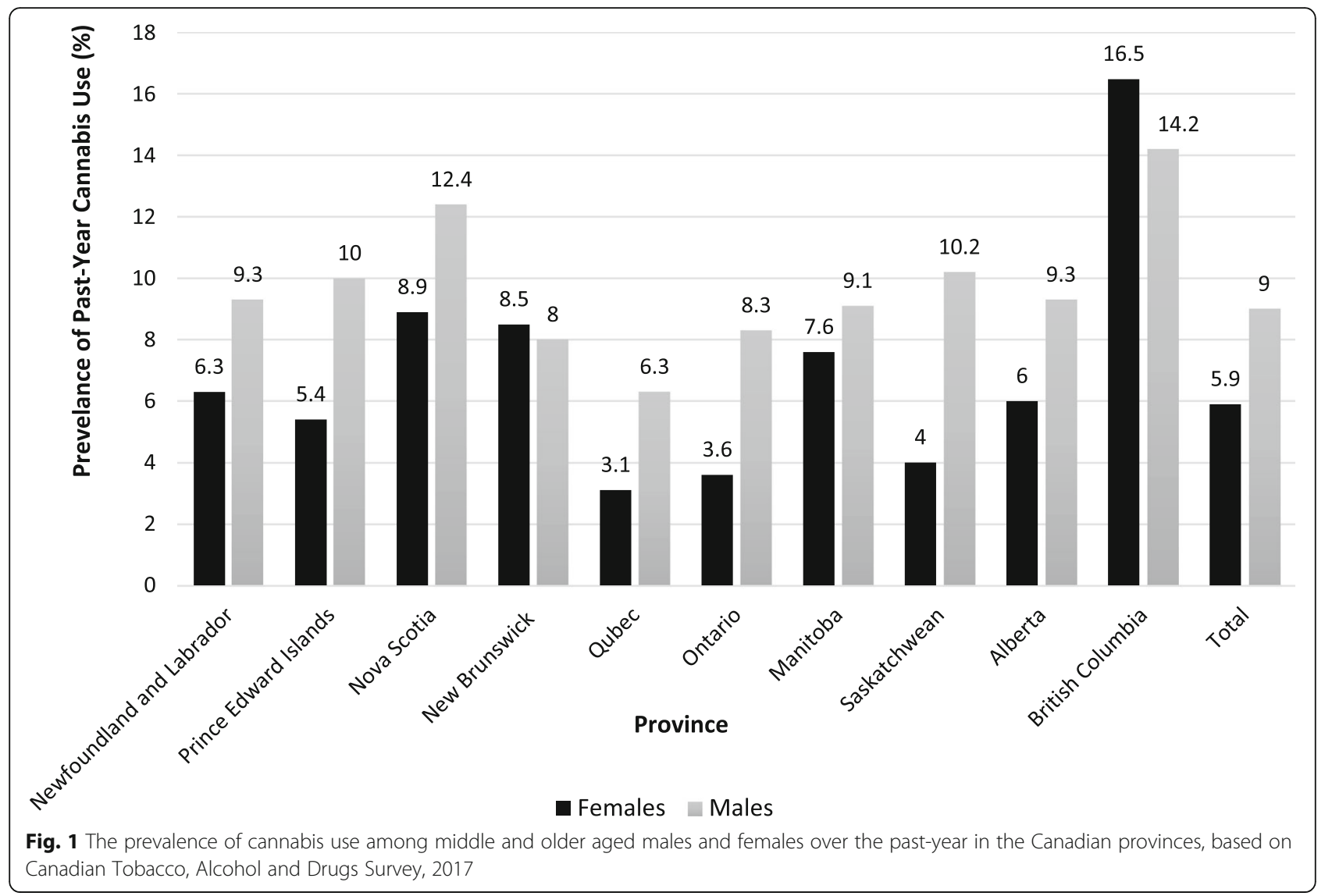

admit to daily or almost daily use. Overall $39.1 \%$ of male's self-report using cannabis for medical purposes. Of these users, $63.5 \%$ report using cannabis for chronic pain, followed by $10.1 \%$ for insomnia, and $7.4 \%$ for anxiety/nerves. The primary way of accessing cannabis was through family members, shared with friends, or grown on their own. Additionally, $61.9 \%$ of males reported a failed attempt at reducing or stopping cannabis use over the past 3 months.

After adjusting for all covariates, statistically significant predictors for male past-year cannabis use are displayed in Table 2. Individuals without a partner were 2.13 times more likely to be past-year cannabis users, as compared to those with partners (OR: 2.13, 95\% CI: 1.1-4.1). Additionally, those who smoked traditional tobacco cigarettes were 4.51 times more likely to be past-year cannabis users, compared to their counterparts (OR: 4.51, 95\% CI: 2.5-8.2). Most notably, illicit drug users were 40.40 times more likely to be past-year cannabis users, compared to those who did not use illicit drugs (OR: 40.40, 95\% CI: 10.0-162.6). There was no concern for multicollinearity as tested by bivariate correlations. The model fit for the middle and older adult male model was 0.23 .

\section{Females}

Of past-year cannabis users, over 30\% report daily or almost daily use (Table 1). Among females, 56\% selfreported using cannabis for medical reasons. Of selfreported medical cannabis users, 52.2\% reported its use for chronic pain, $21.6 \%$ for insomnia, and $8.6 \%$ for pain associated with multiple sclerosis/spinal cord injury. The primary method of accessing cannabis was through family members, from a dispensary, or a licenced medical dealer.

After adjusting for all covariates (Table 3), significant sociodemographic factors of past-year cannabis use among females included residing in British Columbia (OR: 5.50, 95\% CI: 2.4-12.8), or Eastern-Atlantic provinces (OR: 2.63, 95\% CI: 1.4-4.9) as compared to the central provinces. Residing in an urban community also showed strong statistical association with past-year cannabis use (OR: 2.21, 95\% CI: 1.24-3.91) when compared to living in a rural community. Additionally, among health factors, having fair or poor mental health was associated with over a four-fold greater risk of using cannabis in the past-year (OR: 4.29, 95\% CI: 1.1-16.3) as compared to having excellent or very good mental health. When looking at substance use variables, current 
Table 1 Supplementary characteristics (weighted) of cannabis use among middle and older aged males and females who have consumed cannabis over the past-year, based on the 2017 Canadian Tobacco, Alcohol and Drugs Survey

\begin{tabular}{|c|c|c|}
\hline & $\begin{array}{l}\text { Middle and Older Aged Males } \\
\%(\mathrm{~N})\end{array}$ & $\begin{array}{l}\text { Middle and Older Aged Females } \\
\%(\mathrm{~N})\end{array}$ \\
\hline \multicolumn{3}{|l|}{ Frequency of cannabis use (past 3 months) } \\
\hline Less than monthly & $27.1(205,294)$ & $21.1(114,796)$ \\
\hline Monthly & $7.7(58,193)$ & $14.1(76,716$ \\
\hline Weekly & $19.8(150,466)$ & $15.5(84,189)$ \\
\hline Daily or almost daily & $25.5(193,575)$ & $30.9(167,851)$ \\
\hline Not in the past 3 months & $19.9(7,976,914)$ & $18.4(8,806,401)$ \\
\hline \multicolumn{3}{|l|}{ Self-reported cannabis used for medical purposes } \\
\hline Yes & $39.1(301,447)$ & $56.0(307,751)$ \\
\hline No & $60.9(469,543)$ & $44.0(241,833)$ \\
\hline \multicolumn{3}{|c|}{ Main self-reported medical conditions cannabis is used for } \\
\hline Chronic Pain (arthritis, back pain, migraines) & $63.5(191,382)$ & $52.2(160,644)$ \\
\hline Depression & $1.9(5754)$ & $2.1(6509)$ \\
\hline Multiple Sclerosis/Spinal Cord Injury & $1.7(5094)$ & $8.6(26,478)$ \\
\hline Anxiety/Nerves & $7.4(22,191)$ & $3.9(12,126)$ \\
\hline Insomnia & $10.1(30,565)$ & $21.6(66,536)$ \\
\hline Other & $15.4(46,461)$ & $11.5(35,285)$ \\
\hline \multicolumn{3}{|l|}{ Where cannabis is obtained } \\
\hline Grow my own & $11.2(80,975)$ & $4.0(21,118)$ \\
\hline Someone grows it for me (medical or recreational) & $2.2(15,992)$ & $1.1(5889)$ \\
\hline Shared around a group of friends & $11.4(82,593)$ & $3.4(18,346)$ \\
\hline From family members & $39.6(286,431)$ & $49.3(262,171)$ \\
\hline From someone else I know & $6.6(47,592)$ & $6.5(34,474)$ \\
\hline From a dealer (unlicensed) & $8.5(61,623)$ & $5.2(27,631)$ \\
\hline From a licenced medical dealer & $2.9(21,128)$ & $10.1(53,880)$ \\
\hline From a dispensary/compassion club & $12.6(91,271)$ & $14.8(78,975)$ \\
\hline Online & $0.5(3508)$ & 0.7 (3898) \\
\hline Other & $4.4(31,481)$ & $4.8(25,505)$ \\
\hline \multicolumn{3}{|l|}{ How cannabis is consumed } \\
\hline \multicolumn{3}{|l|}{ Smoked a joint, bong, pipe or blunt } \\
\hline Yes & $89.0(674,682)$ & $74.3(404,888)$ \\
\hline No & $11.0(83,645)$ & $25.7(140,164)$ \\
\hline \multicolumn{3}{|l|}{ Mixed with Tobacco (also known as spliff) } \\
\hline Yes & $19.5(148,241)$ & $13.9(75,306)$ \\
\hline No & $80.5(610,085)$ & $86.1(464,834)$ \\
\hline \multicolumn{3}{|l|}{ Eaten in foods (ex. brownies, cake, cookies or candy) } \\
\hline Yes & $33.1(250,761)$ & $45.0(245,161)$ \\
\hline No & $66.9(507,566)$ & $55.0(299,891)$ \\
\hline \multicolumn{3}{|l|}{ Drank in tea, cola, alcohol or other drinks } \\
\hline Yes & $6.0(45,226)$ & $3.1(16,816)$ \\
\hline No & $94.0(713,101)$ & $96.9(528,236)$ \\
\hline \multicolumn{3}{|l|}{ Vaporized with a vaporiser, vape pen or e-cigarette } \\
\hline Yes & $22.4(170,205)$ & $28.8(157,137)$ \\
\hline No & $77.6(588,122)$ & $71.2(387,915)$ \\
\hline
\end{tabular}


Table 1 Supplementary characteristics (weighted) of cannabis use among middle and older aged males and females who have consumed cannabis over the past-year, based on the 2017 Canadian Tobacco, Alcohol and Drugs Survey (Continued)

\begin{tabular}{lll}
\hline & $\begin{array}{l}\text { Middle and Older Aged Males } \\
\%(\mathbf{N})\end{array}$ & $\begin{array}{l}\text { Middle and Older Aged Females } \\
\%(\mathbf{N})\end{array}$ \\
\hline Dabbed & & $4.3(23,188)$ \\
Yes & $8.7(66,045)$ & $95.7(521,863)$ \\
No & $91.3(690,708)$ & $11.6(284)$ \\
Tried and failed to reduce/stop cannabis use (past 3 months) & & $88.4(2156)$ \\
Yes & $61.9(31,005)$ & 24.28 \\
No & $38.1(19,110)$ & \\
Mean age at first use & & 21.04 \\
\hline
\end{tabular}

cigarette smoking was identified as a significant predictor for being a past-year cannabis user as compared to those who did not smoke cigarettes (OR: 2.90, 95\% CI: 1.5-5.6). Moreover, females who reported using other tobacco products were 7.55 times more likely to be past-year cannabis users, compared to those who did not use other tobacco products (OR: 7.55, 95\% CI: 2.325.0). Finally, illicit drug users were also at a significantly greater odds be past-year cannabis users, compared to non-drug users (OR: 6.99, 95\% CI: 1.2-41.8). There was no concern for multicollinearity as tested by bivariate correlations. The model fit for the middle and older aged female model was 0.30 .

\section{Discussion}

The aim of this study was to assess the prevalence, characteristics, and patterns of pre-legalization cannabis use among middle and older aged Canadians, independently for males and females. In 2017, a year before Canadian cannabis legalization, the overall prevalence of past-year cannabis use in middle and older aged adults was $7.4 \%$, which was higher than an earlier analysis conducted in 2012 [16]. In the present study, 9.0\% males and 5.9\% of females reported cannabis use in the past year. When examining the older male subgroup closer, determinants of use include having no partner, being a current cigarette smoker, and being an illicit drug user. Characteristics for older females, include residing in British Columbia or the Eastern-Atlantic provinces, residing in an urban community, suffering from poor mental health, cigarette smoking, using other tobacco products, and illicit drug use. This study clearly illustrates the sex-specific differences in cannabis use among older Canadians, providing baseline data for future studies investigating substance use and disorders among this age cohort and between sexes.

Middle and older aged males reported an increased overall prevalence of past-year cannabis use in 2017. While increased prevalence of cannabis among males was also recently reported in the United States by Hasin et al. [33] the reason for this finding might be multifactorial. Although specific reasons remain debated, it is possible that cultural and behavioural acceptance of learned smoking habits in the male subgroups could be a contributing factor of increased cannabis use [34]. Additionally, it is interesting that our results note $62 \%$ of males who tried to quit or reduce their cannabis intake over the past 3 months, failed to do so (Table 1). These results are in agreeance with other investigations, which note that males have an increased prevalence of cannabis addiction and cannabis use disorders, making it difficult to quit overall cannabis intake [33, 35]. However, a study conducted by Herrmann (2015) highlighted that females were more likely to show more individual withdrawal symptoms, a higher severity, and more discomfort during the cannabis withdrawal process, when compared to males [36]. With increasing rates of cannabis use among females, it would be interesting to examine whether these trends hold true to the older Canadian subsample.

Supplementary characteristics note a high percentage (56\%) of self-reported female medical cannabis users. This is in line with research in rat models that have found female rats to be more sensitive to Tetrahydrocannabinol's (THC) pain blocking effects as compared to their male counterparts [37]. Although previous studies have identified that medical marijuana use is more commonly seen in men [38-40], the trend of heightened mental health disorders among women may be the cause for the increased uptake of medical marijuana use in this population [41]. Additionally, it is important to note the rising popularity of vaporizers, such as e-cigarettes, as a delivery tool among this sample (Table 1). The increased prevalence of ecigarette use has been noted across all age groups and should be monitored carefully given the rise in severe respiratory illnesses in relation to the concomitant use of ecigarettes and cannabis products [28, 42-44].

Among sociodemographic factors, having no partner was a determinant for past-year cannabis use among males. While many studies have reported marital and 


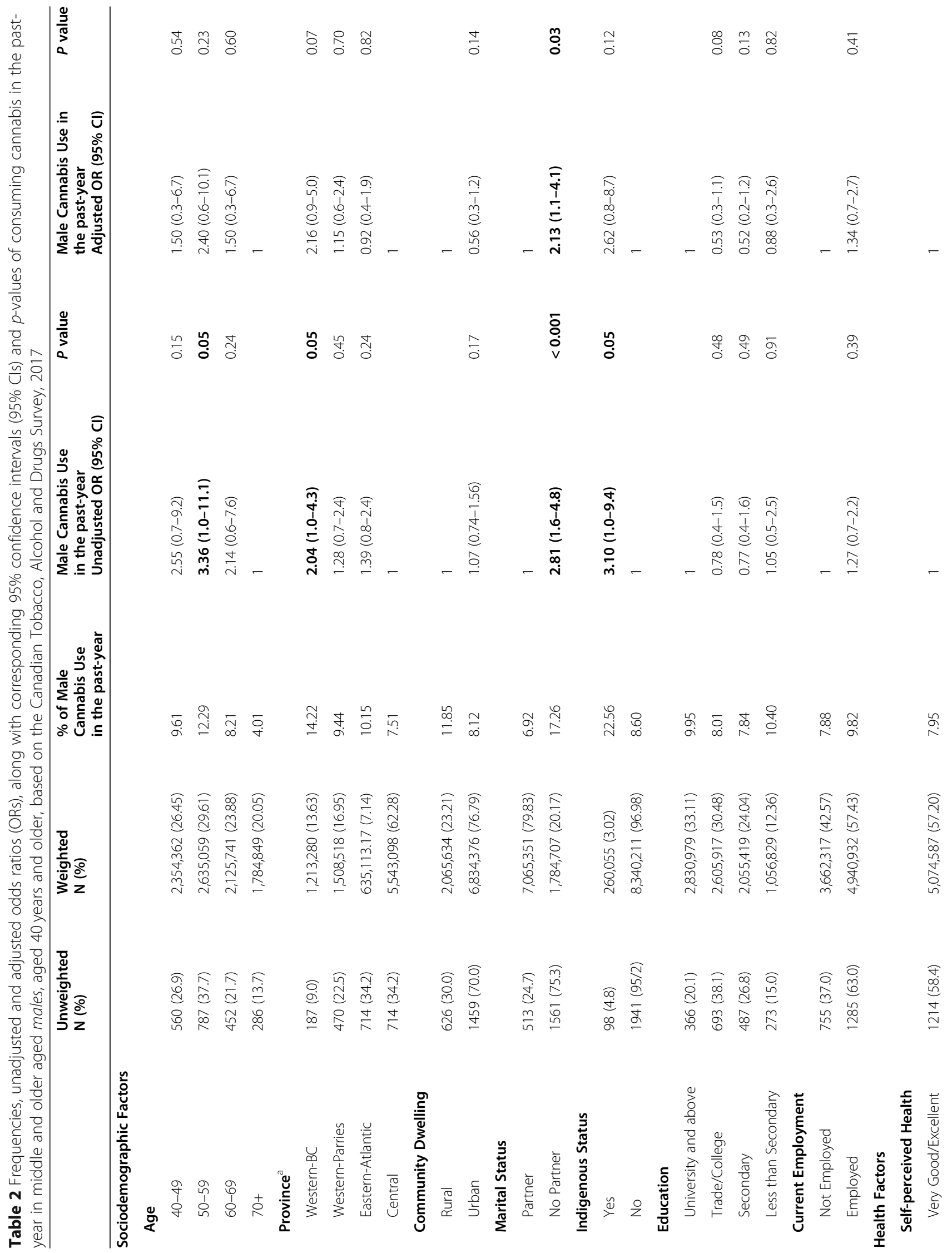




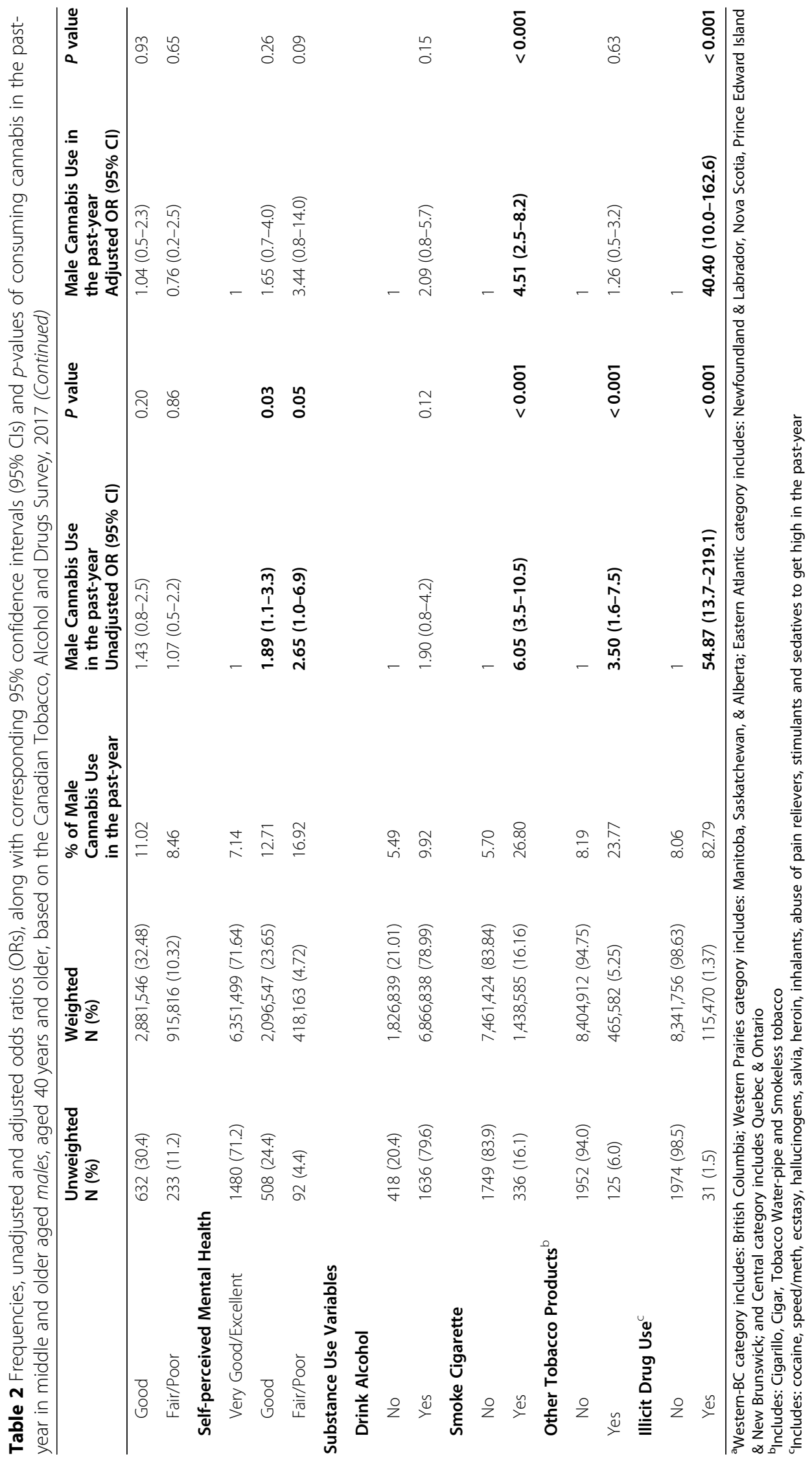




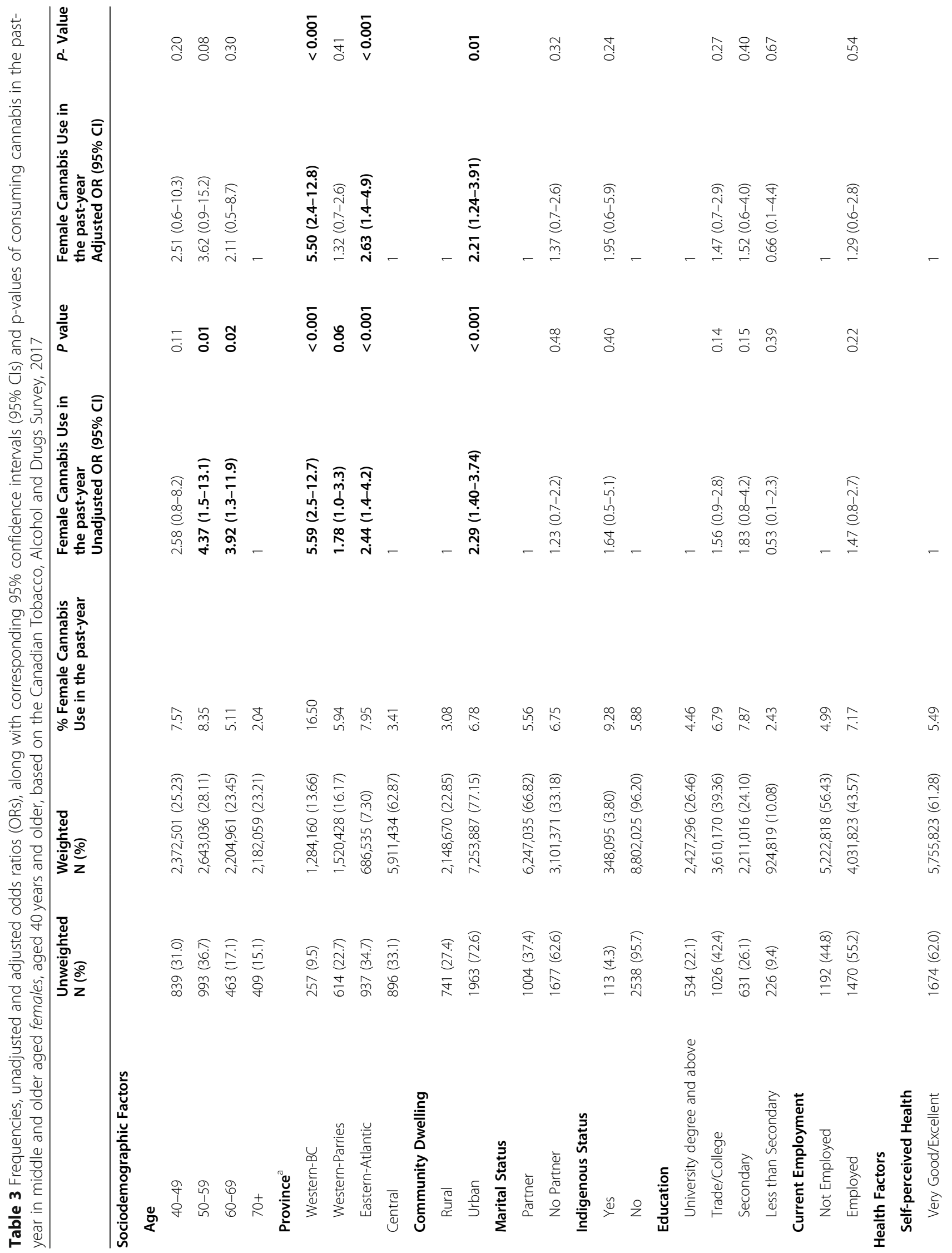




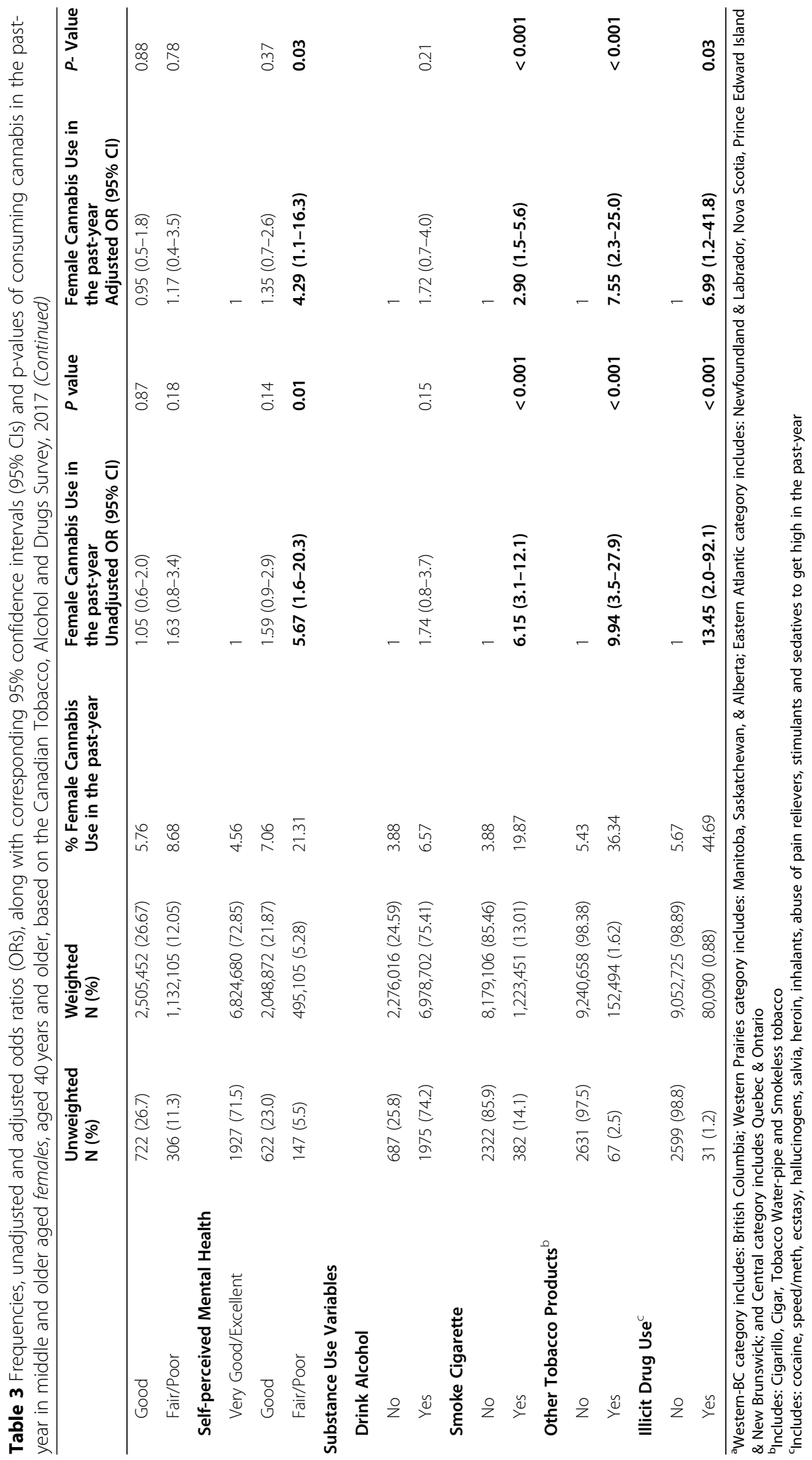


relationship status to be a general predictor of substance use in all sexes [33, 45-47], it is important to note that no other studies have identified such an association to be specific to males. Many factors including the lack of social support, increased leisurely time allowing for more experimental behaviors, and lack of familial commitments, could be contributing to this association $[46,47]$. Having said that, more exploration on the role that marital and romantic relationships in regulating drug usage is necessary.

In females, sociodemographic factors such as residing in urban communities was associated with past-year cannabis use. Hasin et al. (2018) has confirmed the notion of increased cannabis availability and subsequent usage in urban regions [33]. Additionally, a sex-based difference was noted among Slovakian females, that showed riskier substance use in females who reside in urban areas [48]. This study also highlighted that females residing in either British Columbia or the Eastern-Atlantic Provinces are more likely to be past-year cannabis users, compared to the other Canadian provinces. This finding is supported by a previous report by Statistics Canada, which found that British Columbians and Nova Scotians (one of four Eastern-Atlantic Provinces) had significantly higher prevalence of past-year marijuana use compared to other Canadian provinces [16]. Although Canada is one of the largest cannabis cultivators in the world, large quantities of cannabis have been known to be smuggled into Canada through Canadian seas and ports [49-51]. Therefore, the close proximity of British Columbia and Nova Scotia to international shipping ports may make them prime location for illegally shipped contraband.

In regard to health factors, our findings indicate that females who experienced poorer self-reported mental health were more likely to be cannabis users as compared to those who reported very good or excellent mental health. An American study noted that mental well-being among cannabis users was significantly poorer than their non-using counterparts, especially among female users [52]. Although cannabis has been shown to have modest health benefits, long term use has been associated with cognitive impairment [53-55]. The association between using cannabis and adverse mental health outcomes, such as increased depressive symptomology, worsening anxiety, and panic disorders, have been reported previously $[41,56]$. Given that cannabis is often portrayed as a tool to improve mental health, adult cannabis users were likely to over-acknowledge its potential benefits [57, 58]. Therefore, these findings can also be indicative of individuals using cannabis products to manage declining mental health, as a form of selftherapy or prescribed rehabilitation [59]. Given the ambiguity surrounding the long-term effects of cannabis, it is important that public health professionals ensure that using cannabis does not exacerbate existing mental health problems or replace healthier mental health treatments.

Finally, among substance use variables, this study showed increased cannabis use among both male and female illicit drug users. In particular, a study by Han et al. (2017) highlighted the alarming rates of illicit drug use, in association with cannabis use in older populations [60]. While cannabis being a gateway drug into illicit drug use remains highly debated [61-66], there is a general agreement among researchers to monitor the transition of marijuana to more lethal drugs [65-67]. Given that the simultaneous use of multiple substances can make older adults susceptible to declining executive functions [68, 69], it is essential that measures to combat multiple substance use disorders are implemented to prevent additional burden of disease among this population.

Although novel and imperative to the body of substance use literature, this study is subjected to a few limitations. The CTADS relies on self-reported data and therefore is subjected to recall bias. This survey is also unable to capture some important variables including ethnicity and income, which may have influenced cannabis use behaviors in this sample. As is the case for all cross-sectional analyses, causational interpretation of these findings cannot be determined. The CTADS also neglects to include those living on the three Canadian territories and institutionalized populations, including those that are incarcerated, institutionalized, or active in the military. Some of these populations are identified in the literature to be active and substantial users of cannabis, and therefore their exclusion could have altered overall prevalence rates. Regardless of these limitations, this study allows for a large sample size and provides key insights on sex specific trends associated with cannabis use prior to legalization in Canada.

\section{Conclusion}

To our knowledge, this is the first nationally representative Canadian study to outline the prevalence, characteristics, and patterns of cannabis use in middle and older aged adults. In specific, predictors of past-year cannabis use for older and middle-aged males included having no partner, being a current cigarette smoker and illicit drug user. Predictors for females included residing in British Columbia, in the Eastern-Atlantic provinces and in an urban community, having poor mental health, smoking cigarettes, using tobacco products, and illicit drugs. This study highlights the importance of including middle and older aged adults in the discussion around cannabis, in order to create awareness around its use. Results from this study can help identify longitudinal trends of using cannabis in regard to the pre and post legalization era of cannabis in Canada. With the current landscape, it is 
important to further investigate the benefits of regular cannabis use among older Canadians, as well as identify potentials for harms in situations of misuse, overuse, and dependency. Additionally, our results suggest more research is needed around the female mental health and cannabis use, specifically the use of marijuana as a replacement for other beneficial mental health treatments and the potential trigger of worsening symptomology. Furthermore, as the population continues to age, it is important to examine substance use in this group distinctly and implement initiatives to offset any associated comorbidities.

\section{Abbreviations}

CUD: Cannabis Use Disorder; CTADS: Canadian Tobacco, Alcohol and Drugs Survey; OR: Odds Ratio; Cl: Confidence Interval

\section{Acknowledgements}

We thank Akshitha Keethakumar for her critical edits to this paper. We are also thankful for the participants of the Canadian Tobacco, Alcohol and Drugs Survey (CTADS) for providing the responses to the questionnaire, along with Health Canada and Statistics Canada for designing and implementing the survey. Although the research and analysis are based on data from Statistics Canada, and the opinions expressed in this paper do not represent the views of Statistics Canada or the Canadian Research Data Centre Network (CRDCN).

\section{Authors' contributions}

AK was responsible for the study conceptualization, funding acquisition, investigation, data curation, formal analysis, methodology, validation, writing the original draft, reviewing and editing; VMM contributed with the study conceptualization, investigation, validation, critical revision and editing the paper; NK contributed with the methodology and critical revisions of the paper; HT supervised the project and also contributed to the study conceptualization, methodology, review and editing. All authors have read and approved the final version of the manuscript submitted for publication.

\section{Funding}

This research was funded by the LaMarsh Centre for Child and Youth Research, York University. Additionally, AK was the recipient of the OGS Masters Award and VMM the recipient of the CIHR Masters Award. However, the funding bodies had no role in the design, analysis, and interpretation of the data or in the preparation, review, or approval of the manuscript.

\section{Availability of data and materials}

The data collected by Statistics Canada as part of the CTADS 2017 can be accessed through a formal application submitted to Statistics Canada via their website at http://www23.scensus-recensement/imdb/p2SV.pl?Function= getSurvey\&SDDS=4440.

\section{Ethics approval and consent to participate}

Not applicable.

\section{Consent for publication}

Not applicable.

\section{Competing interests}

The authors have no competing interests to declare.

\section{Author details}

${ }^{1}$ School of Kinesiology and Health Sciences, Faculty of Health, York University, Toronto, Canada. ${ }^{2}$ School of Nursing, Faculty of Health, York University, Toronto, Canada.
Received: 18 June 2020 Accepted: 15 December 2020

Published online: 06 January 2021

\section{References}

1. Mahamad S, Hammond D. Retail price and availability of illicit cannabis in Canada. Addict Behav. 2019;90:402-8.

2. Cannabis Legalization and Regulation. https://www.justice.gc.ca/eng/cj-jp/ cannabis/. Accessed 29 Feb 2020

3. Stockwell T, Dorocicz J, Macdonald S, Sherk A, Sorge J, Zhao J. Canadian Substance Use Costs and Harms: 2007-2014. 2007. www.ccsa.ca. Accessed 29 Feb 2020.

4. Canadian Tobacco Alcohol and Drugs (CTADS): 2015 summary - Canada.ca. https://www.canada.ca/en/health-canada/services/canadian-tobaccoalcohol-drugs-survey/2015-summary.html. Accessed 29 Feb 2020.

5. Fergusson DM, Boden JM. Cannabis use and later life outcomes. Addiction. 2008;103:969-76. https://doi.org/10.1111/j.1360-0443.2008.02221.x.

6. Fischer B, Rehm J, Irving H, lalomiteanu A, Fallu JS, Patra J. Typologies of cannabis users and associated characteristics relevant for public health: A latent class analysis of data from a nationally representative Canadian adult survey. Int J Methods Psychiatr Res. 2010;19:110-24. https://doi.org/10.1002/ mpr.307.

7. Marconi A, Di Forti M, Lewis CM, Murray RM, Vassos E. Meta-analysis of the Association Between the Level of Cannabis Use and Risk of Psychosis. Schizophr Bull. 2016;42:1262-9. https://doi.org/10.1093/schbul/sbw003.

8. Hasan A, von Keller R, Friemel CM, Hall W, Schneider M, Koethe D, et al. Cannabis use and psychosis: a review of reviews. Eur Arch Psychiatry Clin Neurosci. 2020;270:403-12. https://doi.org/10.1007/s00406-019-01068-z.

9. Winhusen T, Theobald J, Kaelber DC, Lewis D. Regular cannabis use, with and without tobacco co-use, is associated with respiratory disease. Drug Alcohol Depend. 2019;204:107557.

10. Centre on Substance Use C. Cannabis (Canadian Drug Summary). 2018. www.ccsa.ca•www.ccdus.ca. Accessed 29 Feb 2020.

11. Yayan J, Rasche K. Damaging effects of cannabis use on the lungs. In: Advances in Experimental Medicine and Biology: Springer New York LLC; 2016. p. 31-4.

12. Nkansah-Amankra S. Substance Use \& Misuse Revisiting the Association Between "Gateway Hypothesis" of Early Drug Use and Drug Use Progression: A Cohort Analysis of Peer Influences on Drug Use Progression Among a Population Cohort. Subst Use Misuse. 2020;55:998-1007. https:// doi.org/10.1080/10826084.2020.1720245

13. Leung J, Chan GCK, Hides L, Hall WD. What is the prevalence and risk of cannabis use disorders among people who use cannabis? a systematic review and meta-analysis. Addict Behav. 2020;109:106479.

14. Hajizadeh M. Legalizing and regulating marijuana in Canada: Review of potential economic, social, and health impacts. Int J Health Policy Manag. 2016:5:453-6.

15. Lau N, Sales P, Averill S, Murphy F, Sato SO, Murphy S. A safer alternative: Cannabis substitution as harm reduction. Drug Alcohol Rev. 2015:34:654-9. https://doi.org/10.1111/dar.12275.

16. Rotermann M, Langlois K. Health Reports Prevalence and correlates of marijuana use in Canada, 2012. Heal Reports:2015 www.scensusrecensement. Accessed 29 Feb 2020.

17. Rotermann M. Health Reports Analysis of trends in the prevalence of cannabis use and related metrics in Canada. Heal Reports. 2019. https://doi. org/10.25318/82-003-×201900600001-eng.

18. Blazer DG, Wu L-T. The Epidemiology of Substance Use and Disorders Among Middle Aged and Elderly Community Adults: National Survey on Drug Use and Health (NSDUH). Am J Geriatr Psychiatry. 2009;17:237-45.

19. Fahmy V, Hatch SL, Hotopf M, Stewart R. Prevalences of illicit drug use in people aged 50 years and over from two surveys. Age Ageing. 2012;41:5536. https://doi.org/10.1093/ageing/afs020.

20. Etten ML Van, Neumark YD, Anthony JC. Male-female differences in the earliest stages of drug involvement. Addiction. 1999;94:1413-1419. doi: https://doi.org/10.1046/j.1360-0443.1999.949141312.x.

21. Wagner FA, Anthony JC. Male-female differences in the risk of progression from first use to dependence upon cannabis, cocaine, and alcohol. Drug Alcohol Depend. 2007:86:191-8.

22. Fattore $L$, Altea S, Fratta W. Sex differences in drug addiction: A review of animal and human studies. Women Health. 2008:4:51-65. https://doi.org/10. 2217/17455057.4.1.51. 
23. Pederson A, Greaves L, Poole N. Gender-transformative health promotion for women: A framework for action. Health Promot Int. 2015;30:140-50. https://doi.org/10.1093/heapro/dau083.

24. Barnes AJ, Moore AA, Xu H, Ang A, Tallen L, Mirkin M, et al. Prevalence and correlates of at-risk drinking among older adults: The project SHARE study. J Gen Intern Med. 2010;25:840-6.

25. Moore BA, Augustson EM, Moser RP, Budney AJ. Respiratory effects of marijuana and tobacco use in a U.S. sample. J Gen Intern Med. 2005;20:337.

26. Moore TH, Zammit S, Lingford-Hughes A, Barnes TR, Jones PB, Burke M, et al. Cannabis use and risk of psychotic or affective mental health outcomes: a systematic review. Lancet. 2007;370:319-28.

27. Zuckermann AME, Battista K, De Groh M, Jiang Y, Leatherdale ST. Prelegalisation patterns and trends of cannabis use among Canadian youth: Results from the COMPASS prospective cohort study. BMJ Open. 2019;9: e026515.

28. Mehra VM, Keethakumar A, Bohr YM, Abdullah P, Tamim H. The association between alcohol, marijuana, illegal drug use and current use of E-cigarette among youth and young adults in Canada: Results from Canadian Tobacco, Alcohol and Drugs Survey 2017. BMC Public Health. 2019;19:1-10.

29. Lau N, Sales P, Averill S, Murphy F, Sato SO, Murphy S. Responsible and controlled use: Older cannabis users and harm reduction. Int J Drug Policy. 2015;26:709-18.

30. Census Profile, 2016 Census - Canada [Country] and Canada [Country]. https://www12.scensus-recensement/census-recensement/2016/dp-pd/prof/ details/page.ffm?Lang $=\mathrm{E} \&$ Geo $1=$ PR\&Code $1=01 \&$ Geo2 $=$ PR\&Code2 $=$ $01 \&$ Data $=$ Count\&SearchText $=01 \&$ SearchType $=$ Begins\&SearchPR $=$ $01 \& B 1=$ All\&Custom $=\& T A B I D=3$. Accessed 29 Feb 2020.

31. Surveys and statistical programs - Canadian Tobacco, Alcohol and Drugs Survey (CTADS). https://www23.scensus-recensement/imdb/p2SV.pl? Function $=$ getSurvey $\&$ SDDS $=4440$. Accessed 29 Feb 2020

32. Cuschieri S. The STROBE guidelines. Saudi J Anaesth. 2019;13:S31-4. https://doi.org/10.4103/sja.SJA_543_18.

33. Hasin DS, Shmulewitz D, Sarvet AL. Time trends in US cannabis use and cannabis use disorders overall and by sociodemographic subgroups: a narrative review and new findings. Am J Drug Alcohol Abuse. 2019;45:62343 .

34. Higgins ST, Kurti AN, Redner R, White TJ, Gaalema DE, Roberts ME, et al. A literature review on prevalence of gender differences and intersections with other vulnerabilities to tobacco use in the United States, 2004-2014. Prev Med. 2015;80:89-100

35. Zhu H, Wu L-T. Sex Differences in Cannabis Use Disorder Diagnosis Involved Hospitalizations in the United States. J Addict Med. 2015;11:357-67. https:// doi.org/10.1097/ADM.0000000000000330.

36. Herrmann ES, Weerts EM, Vandrey R. Sex differences in cannabis withdrawal symptoms among treatment-seeking cannabis users. Exp Clin Psychopharmacol. 2015;23:415.

37. Marusich JA, Craft RM, Lefever TW, Wiley JL. The impact of gonadal hormones on cannabinoid dependence. Exp Clin Psychopharmacol. 2015; 23:206-16.

38. Fairman BJ. Trends in registered medical marijuana participation across 13 US states and District of Columbia. Drug Alcohol Depend. 2016;159:72-9.

39. Zaller N, Topletz A, Frater S, Yates G, Lally M, Yates GA. Profiles of Medicinal Cannabis Patients Attending Compassion Centers in Rhode Island. J Psychoactive Drugs. 2015;47:18-23. https://doi.org/10.1080/02791072.2014. 999901.

40. Reinarman C, Nunberg H, Lanthier F, Heddleston T. Who Are Medical Marijuana Patients? Population Characteristics from Nine California Assessment Clinics. J Psychoactive Drugs. 2011;43:128-35. https://doi.org/10. 1080/02791072.2011.587700.

41. Riecher-Rössler A. Sex and gender differences in mental disorders. Lancet Psychiatry. 2017;4:8-9. https://doi.org/10.1016/S2215-0366(16)30348-0.

42. Kalkhoran S, Chang Y, Rigotti NA. Online Searches for Quitting Vaping During the 2019 Outbreak of E-cigarette or Vaping Product Use-Associated Lung Injury. J Gen Intern Med. 2020. https://doi.org/10.1007/s11606-020 05686-5.

43. Outbreak of Lung Injury Associated with the Use of E-Cigarette, or Vaping Products | Electronic Cigarettes | Smoking \& Tobacco Use | CDC. https:// www.cdc.gov/tobacco/basic_information/e-cigarettes/severe-lung-disease. html\#latest-outbreak-information. Accessed 4 Mar 2020.
44. Lee MH, Hancox RJ. Expert Review of Respiratory Medicine Effects of smoking cannabis on lung function. Expert Rev Respir Med. 2011;5:537-47. https://doi.org/10.1586/ers.11.40.

45. Xie M, Gupta MK, Archibald SD, Stanley Jackson B, Young JEM, Zhang H. Marijuana and head and neck cancer: an epidemiological review. J Otolaryngol Head Neck Surg. 2018;47:73. https://doi.org/10.1186/s40463018-0319-2.

46. Fleming $\mathrm{CB}$, White $\mathrm{HR}$, Catalano RF. Romantic relationships and substance use in early adulthood: an examination of the influences of relationship type, partner substance use, and relationship quality. J Health Soc Behav. 2010;51:153-67. https://doi.org/10.1177/0022146510368930.

47. Aylaz R, Aktürk Ü, Erci B, Öztürk H, Aslan H. Relationship between depression and loneliness in elderly and examination of influential factors. Arch Gerontol Geriatr. 2012;55:548-54.

48. Pitel L, Geckova AM, Vandijk JP, Reijneveld SA. Degree of urbanization and gender differences in substance use among Slovak adolescents. Int J Public Health. 2011;56:645-51.

49. Bouchard M. Towards a realistic method to estimate cannabis production in industrialized countries. Contemp Drug Probl. 2009;35:291-32.

50. Schneider S. Organized contraband smuggling and its enforcement in Canada: An assessment of the anti-smuggling initiative. Trends Organ Crime. 2009;6:3-21. https://doi.org/10.1007/s12117-000-1012-0.

51. Mawani F, Maslov A, Lawrence A. Measuring Illicit Cannabis Seizures in Canada Methods, Practices and Recommendations. 2017. www.publicsafety. gc.ca. Accessed 29 Feb 2020.

52. Lev-Ran S, Imtiaz S, Taylor BJ, Shield KD, Rehm J, Le Foll B. Gender differences in health-related quality of life among cannabis users: Results from the national epidemiologic survey on alcohol and related conditions. Drug Alcohol Depend. 2012;123:190-200.

53. Broyd SJ, Van Hell HH, Beale C, Yücel M, Solowij N. Acute and chronic effects of cannabinoids on human cognition - A systematic review. Biol Psychiatry. 2016;79:557-67.

54. Volkow ND, Baler RD, Compton WM, Weiss SRB. Adverse health effects of marijuana use. New Engl J Med. 2014;370:2219-27. https://doi.org/10.1056/ NEJMra1402309.

55. Pratt M, Stevens A, Thuku M, Butler C, Skidmore B, Wieland LS, et al. Benefits and harms of medical cannabis: A scoping review of systematic reviews. Syst Rev. 2019;8:320. https://doi.org/10.1186/s13643-019-1243-x.

56. Turna J, Simpson W, Patterson B, Lucas P, Van Ameringen M. Cannabis use behaviors and prevalence of anxiety and depressive symptoms in a cohort of Canadian medicinal cannabis users. J Psychiatr Res. 2019;111:134-9.

57. Pearson G. Normal drug use: Ethnographic fieldwork among an adult network of recreational drug users in inner London. In: Substance Use and Misuse: Taylor \& Francis; 2001. p. 167-200.

58. Hathaway AD, Comeau NC, Erickson PG. Cannabis normalization and stigma: Contemporary practices of moral regulation. Criminol Crim Just. 2011;11:451-69. https://doi.org/10.1177/1748895811415345.

59. Whiting PF, Wolff RF, Deshpande S, Di Nisio M, Duffy S, Hernandez AV, et al. Cannabinoids for medical use: A systematic review and meta-analysis. JAMA. 2015;313:2456-73

60. Han BH, Sherman S, Mauro PM, Martins SS, Rotenberg J, Palamar JJ. Demographic trends among older cannabis users in the United States, 2006-13. Addiction. 2017;112:516-25. https://doi.org/10.1111/add.13670.

61. Tarter RE, Kirisci L, Mezzich A, Ridenour T, Fishbein D, Horner M, et al. Does the "gateway" sequence increase prediction of cannabis use disorder development beyond deviant socialization? Implications for prevention practice and policy. Drug Alcohol Depend. 2012;123(SUPPL.1):S72-8.

62. Malone PS, Lamis DA, Masyn KE, Northrup TF. A dual-process discrete-time survival analysis model: Application to the gateway drug hypothesis. Multivar Behav Res. 2010;45:790-805

63. Tarter RE, Vanyukov M, Kirisci L, Reynolds M, Clark DB. Predictors of Marijuana Use in Adolescents Before and After Licit Drug Use: Examination of the Gateway Hypothesis. Am J Psychiatry. 2006;163:2134-40. https://doi. org/10.1176/ajp.2006.163.12.2134.

64. Golub A, Johnson BD. The shifting importance of alcohol and marijuana as gateway substances among serious drug abusers. J Stud Alcohol. 1994;55: 607-14

65. Hall WD, Lynskey M. Is cannabis a gateway drug? Testing hypotheses about the relationship between cannabis use and the use of other illicit drugs. Drug Alcohol Rev. 2005;24:39-48. https://doi.org/10.1080/ 09595230500126698 
66. Fergusson DM, Horwood LJ. Does cannabis use encourage other forms of illicit drug use? Addiction. 2000;95:505-20. https://doi.org/10.1046/j.13600443.2000.9545053.x.

67. Secades-Villa R, Garcia-Rodríquez O, Jin CJ, Wang S, Blanco C. Probability and predictors of the cannabis gateway effect: A national study. Int J Drug Policy. 2015;26:135-42.

68. Choi NG, Marti CN, DiNitto DM, Choi BY. Older adults' marijuana use, injuries, and emergency department visits. Am J Drug Alcohol Abuse. 2018; 44:215-23. https://doi.org/10.1080/00952990.2017.1318891.

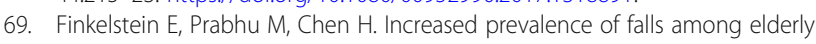
individuals with mental health and substance abuse conditions. Am J Geriatr Psychiatry. 2007;15:611-9.

\section{Publisher's Note}

Springer Nature remains neutral with regard to jurisdictional claims in published maps and institutional affiliations.

Ready to submit your research? Choose BMC and benefit from:

- fast, convenient online submission

- thorough peer review by experienced researchers in your field

- rapid publication on acceptance

- support for research data, including large and complex data types

- gold Open Access which fosters wider collaboration and increased citations

- maximum visibility for your research: over $100 \mathrm{M}$ website views per year

At BMC, research is always in progress.

Learn more biomedcentral.com/submissions 